Pharmaciana

Vol.7, No.2, Nov 2017, Hal. 249-256

ISSN: 2088 4559; e-ISSN: 24770256

\title{
In vitro penetration of alpha arbutin niosome span 60 system in gel preparation
}

\section{Penetrasi alpha arbutin sistem niosom span 60 dalam sediaan gel secara in vitro}

\author{
Rise Desnita*, Sri Luliana, Silvana Anggraini \\ Fakultas Kedokteran Universitas Tanjungpura \\ Jl. Prof. Dr. H. Hadari Nawawi, Bansir Laut, Pontianak
}

Submitted: 12-07-2017

Reviewed: 08-08-2017

Accepted: 14-09-2017

\begin{abstract}
ABSTRAK
Alpha arbutin merupakan senyawa hidrofilik yang sulit melewati stratum korneum. Salah satu upaya dalam meningkatkan penetrasi obat melalui stratum korneum ialah dengan dibuat sistem niosom. Penelitian ini bertujuan mengetahui konsentrasi optimal span 60 dalam meningkatkan efisiensi penjeratan niosom dan mengetahui peningkatan penetrasi alpha arbutin dalam sediaan gel niosom secara in vitro. Niosom terdiri dari campuran span 60 dan kolesterol yang dibuat dengan metode hidrasi lapis tipis. Konsentrasi span 60 divariasikan dalam tiga formula yakni 100, 150 dan $200 \mu$ mol. Sediaan gel dibuat dalam dua formula yaitu formula gel niosom alpha arbutin dan gel alpha arbutin. Uji efisiensi penjeratan menggunakan metode dialysis tubing cellulose membrane. Uji penetrasi secara in vitro menggunakan sel difusi franz tipe flow-trough dengan lepasan kulit ular. Hasil penentuan efisiensi penjeratan menunjukkan formula $100 \mu \mathrm{moL}$ memiliki efisiensi penjeratan optimal yakni sebesar $99,09 \% \pm 0,17$. Hasil uji penetrasi secara in vitro dengan membran lepasan kulit ular menunjukkan penggunaan span 60 sebagai penyusun niosom dalam sediaan gel dapat meningkatkan penetrasi alpha arbutin dengan jumlah kumulatif persen difusi selama 8 jam sebesar 91,62\% $\pm 2,32$ dibandingkan gel alpha arbutin tanpa sistem niosom yakni sebesar 73,00\% $\pm 0,94$.
\end{abstract}

Kata kunci : niosom, alpha arbutin, span 60, penetrasi in vitro

\begin{abstract}
Alpha arbutin is a hydrophilic compound which is difficult to pass trough the stratum corneum. One of the effort to increase the penetration of the drug through the stratum corneum is by making in niosome system. This study aims to determine the optimum concentration of span 60 to improve the entrapment efficiency of niosome and investigate the increasing penetration of alpha arbutin using the niosome system in the preparation of the gel in vitro. Niosome consist a mixture of span 60 and cholesterol it made by thin layer hydration method. Concentration of span 60 was varied into three formulas were 100, 150 and $200 \mu \mathrm{moL}$. The formulation of gel was made in two formulas including formulation of niosome alpha arbutin and alpha arbutin in gel. The determination of enterapment efficiency showed that formula $100 \mu \mathrm{mol}$ has an optimum enterapment efficiency by $99.09 \% \pm 0.17$.
\end{abstract}

\footnotetext{
Penulis korespondesi:

Rice Desnita

Fakultas Kedokteran Universitas Tanjungpura

Jl. Prof.Dr.H. Hadari Nawawi, Bansir Laut,Pontianak

Email:risedesnita@gmail.com
} 
The in vitro penetration tests with shed snake skin membrane showed that usage span 60 as a niosome composer could increase penetration of alpha arbutin in gel formulation with cumulative numbers of diffusion in 8 hours was $91.62 \% \pm 2.32$ compared to alpha arbutin in gel without niosome system about $73.00 \% \pm 0.94$.

Keyword: niosome, alpha arbutin, span 60, in vitro penetration

\section{PENDAHULUAN}

Alpha arbutin adalah metabolit sekunder golongan glikosida fenolik yang bertindak sebagai whitening agent dengan menghambat sintesis melanin berlebih di dalam kulit. Alpha arbutin mempunyai kendala yakni sulitnya berpenetrasi ke dalam kulit karena sifatnya yang hidrofilik. Salah satu usaha dalam mengatasi permasalahan ini ialah dengan dibuat sistem vesikel yaitu niosom. Niosom dapat bertindak sebagai enhancer dengan mempengaruhi konformasi lipid bilayer stratum korneum akibatnya fungsi barier stratum korneum akan menurun (Choi dan Maibach, 2005).

Niosom tersusun dari kolesterol dan surfaktan nonionik sebagai komponen utamanya. Surfaktan dengan nilai HLB antara 4 sampai 8 cenderung memiliki kemampuan untuk membentuk vesikel (Sahin, 2007). Span 60 merupakan surfaktan nonionik yang sering digunakan sebagai penyusun niosom dengan nilai HLB 4,7 (Rowe et al., 2009). Berdasarkan penelitian (Rahman et al., 2011) menunjukkan Span 60 memiliki kemampuan penjerapan terbaik dibandingkan span 20 dan span 80 yakni sebesar $66,16 \%$. Oleh karenanya, tujuan dari penelitian ini adalah untuk mengetahui konsentrasi optimal span 60 yang dapat meningkatkan efisiensi penjeratan niosom dan mengetahui peningkatan penetrasi alpha arbutin dalam sediaan gel niosom secara in vitro.

Alpha arbutin diformulasikan dengan sistem niosom dalam bentuk sediaan gel. Sediaan gel dipilih karena memberikan kontak yang lama pada kulit dan mampu berpenetrasi lebih jauh dalam lapisan kulit (Lund, 1994). Niosom dibuat menggunakan metode klasik hidrasi lapis tipis. Niosom yang diperoleh akan dikarakterisasi, dibuat sediaan gel dan diuji penetrasinya menggunakan sel difusi Franz.

\section{METODE PENELITIAN}

\section{Alat dan Bahan}

Alat yang digunakan adalah rotavapor (Yamato) magnetic stirrer (As One Rexim RSH 1-DR), mikroskop optik (Zeiss Primo Star) dan kamera (Axiocam dengan Image J), pH meter (Hanna), spektrofotometer UV-VIS (Shimadzu 2450), Pompa peristaltik (Watson Marlow), sel difusi franz tipe flow through, Particle Size Analyzer (Backman Coulter). Bahan yang digunakan adalah alpha arbutin (Sigma aldrich), Span 60 (Sigma aldrich), kolesterol (Sigma aldrich), kloroform p.a (Merck), viskolam MAC 10, DMDM hidantoin (Sharon), trietanolamin (TEA) (Clorogreen), aquadest, dialysis tubing cellulose membrane type D9777-100 FT cut off 14000 dan membran lepasan kulit ular (Phyton reticulatus).

\section{Jalannya Penelitian \\ Pembuatan niosom}

Niosom dibuat menggunakan metode klasik hidrasi lapis tipis. Formulasi niosom alpha arbutin dapat dilihat pada Tabel I.

Span 60 dan kolesterol dilarutkan dalam kloroform $10 \mathrm{~mL}$ hingga larut dalam labu alas bulat $100 \mathrm{~mL}$ dan dievaporasi menggunakan rotavapor dalam kondisi vakum pada suhu $40 \pm 2^{\circ} \mathrm{C}$ dengan kecepatan $150 \mathrm{rpm}$ hingga terbentuk lapis tipis. Labu yang berisi lapis tipis dimasukkan ke dalam desikator dan dibiarkan selama 24 jam. Lapis tipis niosom dihidrasi dengan larutan alpha arbutin dalam air kadar $10 \mathrm{mg} / \mathrm{mL}$. Kemudian dievaporasi tanpa kondisi vakum dengan suhu $60 \pm 2^{\circ} \mathrm{C}$ pada kecepatan rotavapor $150 \mathrm{rpm}$ sampai lapis tipis tidak tertinggal dilabu alas bulat. Selanjutnya diaduk dengan pengaduk magnetik (As One) selama 1 jam dengan kecepatan $1000 \mathrm{rpm}$. 
Tabel I. Formula niosom alpha arbutin

\begin{tabular}{cccc}
\hline Bahan & \multicolumn{3}{c}{ Formula } \\
& Formula A & Fomula B & Formula C \\
\hline Alpha arbutin $(\mathrm{mg} / \mathrm{mL})$ & 10 & 10 & 10 \\
Span $60(\mu \mathrm{moL})$ & 100 & 150 & 200 \\
Kolestrol $(\mu \mathrm{moL})$ & 20 & 30 & 40 \\
\hline
\end{tabular}

\section{Pengujian efisiensi penjeratan}

Metode penetapan efisiensi penjeratan dilakukan dengan tujuan untuk menghitung kadar alpha arbutin yang tidak terjerat menggunakan metode dialysis tubing cellulose membrane dengan cut off 14.000. Larutan sampel sebanyak $2 \mathrm{~mL}$ dimasukkan ke dalam membran dialisis yang telah direndam 24 jam. Medium penerima yang digunakan aquadest sebanyak $200 \mathrm{~mL}$ dan diaduk dengan pengaduk magnetik (As One). Penentuan efisiensi penjeratan dilakukan selama 4 jam dan diukur kadarnya dengan spektofotometer UV-Vis dilakukan dengan spektrofotometer UV-Vis pada panjang gelombang $282 \mathrm{~nm}$. Berikut rumus perhitungan efisiensi penjeratan (\%EP) (Rahman et al.,2011) :

$$
\% \mathrm{EP}=\frac{\text { Iumlah obat dalam formula-Iumlah obat yang tidakterjerat }}{\text { Iumlah obat dalam formula }} \times 100 \%
$$

\section{Pengukuran ukuran vesikel niosom}

Pengamatan ukuran vesikel niosom dilakukan mengunakan Particle Size Analyzer (PSA) (Beckman Coulter) dan mikroskop optik (Zeiss Primo Star AxioCamERc Ss) dengan kamera (Axiocam dengan Image J) untuk mengamati ukuran partikel dan bentuk vesikel niosom.

\section{Formulasi sediaan gel dan Uji sifat fisik gel}

Formula gel niosom alpha arbutin dibuat dengan menambahkan DMDM hidantoin ke dalam niosom alpha arbutin kemudian dicampurkan dengan basis gel viskolam MAC 10 sambil diaduk perlahan. Jumlah niosom alpha arbutin yang dimasukkan ke dalam sediaan gel sebesar $10 \mathrm{mg} / \mathrm{mL}$. Formula gel alpha arbutin dibuat dengan menambahkan DMDM hidantoin kedalam larutan alpha arbutin kemudian dicampurkan dengan basis gel viskolam MAC 10 sambil diaduk perlahan. Formula sediaan tersaji pada Tabel II.

Tabel II. Formula sediaan gel niosom alpha arbutin dan gel alpha arbutin

\begin{tabular}{lcc}
\hline \multicolumn{1}{c}{ Bahan } & Gel Niosom Alpha Arbutin & Gel Alpha Arbutin \\
\hline Niosom alpha arbutin $(\mathrm{mg} / \mathrm{mL})$ & 10 & - \\
Alpha arbutin $(\mathrm{mg} / \mathrm{mL})$ & - & 10 \\
DMDM hidantoin $(\mathrm{gram})$ & 0,06 & 0,06 \\
Basis gel (gram) & Add 10 & Add 10 \\
\hline
\end{tabular}

Gel yang telah jadi selanjutnya dilakukan uji organoleptik dan penetapan $\mathrm{pH}$, sebagai berikut:

a. Pengamatan organoleptik, dari sediaan dilakukan dengan mengamati perubahan-perubahan bentuk, warna dan bau sediaan (Septiani and Mita, 2011).

b. Penetapan $\mathrm{pH}$, dilakukan pada sediaan gel menggunakan $\mathrm{pH}$ meter. Rentang nilai $\mathrm{pH}$ yang aman untuk kulit atau sediaan setengah padat adalah sekitar 4,5-6,5 (Soeratri et al., 2005)

\section{Uji difusi gel}

Uji difusi dilakukan secara in vitro dengan sel difusi flow-through menggunakan lepasan kulit ular. Cairan penerima (kompartemen reseptor) yang digunakan ialah aquadest dengan suhu $37 \pm 0.5^{\circ} \mathrm{C}$ sebanyak $50 \mathrm{~mL}$. Sediaan gel ditimbang $500 \mathrm{mg}$ dan diletakan di atas membran kulit ular, cairan 
penerima dialirkan melewati bagian bawah membran lepasan kulit dengan pompa peristaltik. Pada interval waktu jam 0,5: 1: 2: 3: 4: 5: 6: 7 dan 8 diambil sebanyak $5 \mathrm{~mL}$ cairan penerima dan diganti dengan aquadest dengan volume yang sama. Sampel diukur serapannya dengan spektrofotometer UVVis. Persen difusi dapat dihitung dengan rumus sebagai berikut :

$$
\% \text { Difusi }=\frac{\text { Iumlah obat dalam kompartemen reseptor }}{\text { Iumlah obat ditambahkan formula }} \times 100 \%
$$

\section{HASIL DAN PEMBAHASAN}

\section{Pembuatan niosom}

Niosom dibentuk dari surfaktan nonionik dan kolesterol menggunakan metode hidrasi lapis tipis. Metode hidrasi lapis tipis dipilih karena prosesnya mudah dan kompatibel dengan bahan penyusun niosom. Surfaktan nonionik yang digunakan adalah span 60 (sorbitan monostearat) karena secara struktur span 60 memiliki rantai alkil yang panjang dan bersifat hidrofobik serta mempunyai ukuran kepala yang kecil sehingga dapat membentuk lapisan rangkap vesikel. Konsentrasi span 60 yang digunakan untuk pembuatan niosom berada pada rentang 100, 150 dan $200 \mu$ mol. Pembuatan niosom menggunakan kolesterol sebagai pencegah kebocoran vesikel yang bekerja dengan cara mengisi barisan molekul lipid (Rahman et al., 2011). Niosom yang dihasilkan tidak berbau, berwarna putih susu dan Penentuan formula yang dipilih dan digunakan berdasarkan persentase efisiensi penjerapan yang paling tinggi.

\section{Pengujian efisiensi penjeratan}

Efisiensi penjeratan niosom alpha arbutin menggunakan metode dialysis tubing cellulose membrane dengan tujuan untuk menentukan kadar alpha arbutin yang tidak terjerat di dalam niosom. Alpha arbutin yang tidak terjerat dalam niosom akan keluar melalui pori-pori membran dialisis. Hasil analisis statistik yang diperoleh pada ketiga formula niosom menunjukkan tidak terdapat perbedaan signifikan antara ketiga formula sehingga dari ketiga formula niosom yang tersaji pada Tabel III dipilih formula A konsentrasi 100:20 ( $\mu \mathrm{moL}$ ) dengan nilai efisiensi penjeratan sebesar 99,09\% $\pm 0,17$. Selain itu pemilihan formula tersebut untuk mengefisiensikan bahan yang digunakan.

Tabel III. Hasil efisiensi penjeratan niosom alpha arbutin

\begin{tabular}{ccc}
\hline Formula & $\begin{array}{c}\text { Konsentrasi span } \\
\mathbf{6 0 : k o l e s t e r o l ~}(\boldsymbol{\mu m o L})\end{array}$ & $\begin{array}{c}\text { Rata-rata efisiensi penjeratan }(\%) \pm \\
\text { SD }\end{array}$ \\
\hline Formula A & $100: 20$ & $99,09 \pm 0,17$ \\
Formula B & $150: 30$ & $99,07 \pm 0,12$ \\
Formula C & $200: 40$ & $99,31 \pm 0,01$ \\
\hline
\end{tabular}

\section{Pengukuran ukuran vesikel niosom}

Hasil pengukuran vesikel dengan Particle Size Analyzer (PSA) menunjukkan diameter rata-rata partikel niosom yang diperoleh $4657,3 \pm 1236,5 \mathrm{~nm}$. Pengujian ukuran partikel juga dilakukan secara mikroskopik yang tersaji pada Gambar 1, menunjukkan ukuran partikel yang dihasilkan berada pada rentang 2-5 $\mu \mathrm{m}(2000-5000 \mathrm{~nm})$ dengan bentuk bulat atau sferis. Niosom dengan ukuran tersebut adalah jenis vesikel multilamellar (MLV) karena berada pada rentang ukuran 0,5-10 $\mu$ m. Berikut hasil pengukuran niosom tersaji pada Gambar 1: 


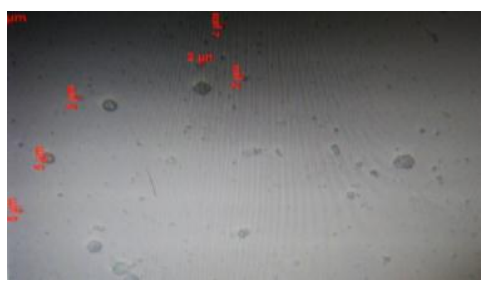

\section{Gambar 1. Foto niosom (perbesaran 40x) menggunakan mikroskop pada formula dengan Konsentrasi span 60:kolesterol (100:20 $\mu \mathrm{moL})$}

Niosom multilamellar adalah niosom yang terdiri dari beberapa lapisan lipid bilayer (Kshitij et al., 2013). Selain data ukuran partikel dari hasil analisis dengan PSA juga diperoleh data indeks polidispers (IP). Indeks polidispers menunjukkan distribusi ukuran partikel dimana rentang indeks polidispers berada diantara 0-1. Nilai indeks polidispers yang berada pada rentang dibawah 0,5 menunjukkan distribusi ukuran partikel yang homogen sedangkan nilai indeks polidispers yang melebihi 0,5 menunjukkan distribusi ukuran partikel yang heterogen (Avadi, 2010). Hasil indeks polidispers diperoleh sebesar 0,203 yang mana menunjukkan distribusi partikel yang homogen atau seragam.

\section{Formulasi sediaan gel dan uji sifat fisik}

Pembuatan sediaan gel niosom alpha arbutin dan gel alpha arbutin menggunakan basis gel viskolam MAC 10 dengan konsentrasi 8\%. Viskolam MAC 10 dipilih sebagai basis gel karena tidak bereaksi dengan komponen lain dalam formula dan terbukti memiliki stabilitas baik dalam penyimpanan disuhu kamar maupun climatic chamber (Lusi, 2015). Viskolam MAC 10 dapat membentuk basis gel setelah ditambahkan TEA sebanyak 4 tetes. Penambahan trietanolamin (TEA) akan meningkatkan suasana $\mathrm{pH}$ viskolam MAC 10 dalam aquadest akibatnya viskolam MAC 10 akan mengembang dan membentuk masa gel karena meningkatnya viskositas. Viskolam MAC 10 dapat membentuk massa gel pada pH 6-7 (Lestiawati, 2015). DMDM hidantoin merupakan bahan pengawet yang umum digunakan pada sediaan kosmetik dan memiliki aktivitas antimikroba dengan spektrum luas (Kailas dan Wendy, 2003). DMDM hidantoin juga merupakan bahan pengawet yang kompatibel dengan surfaktan nonionik.

Sediaan gel yang dihasilkan selanjutnya dilakukan evaluasi sifat fisik yang meliputi pemeriksaan organoleptik dan pengujian $\mathrm{pH}$. Pengamatan organoleptik dilakukan dengan mengamati perubahan bentuk, warna dan bau sediaan gel. Pengamatan secara organoleptik menunjukkan bahwa sediaan gel niosom alpha arbutin yang dihasilkan memiliki karakteristik berwarna putih susu, tidak berbau dan dengan konsistensi masa gel yang kental sedangkan hasil uji organoleptik pada sediaan gel alpha arbutin tanpa sistem niosom menunjukkan gel yang cenderung lebih jernih, tidak berbau dan dengan konsistensi masa gel yang tidak terlalu kental. Perbedaan organoleptik tersebut dapat dipengaruhi adanya niosom yang ditambahkan, karena niosom yang dihasilkan cenderung berwarna putih susu dan kental. Uji sifat fisik selanjutnya ialah pengujian $\mathrm{pH}$ sediaan gel. Pengujian $\mathrm{pH}$ pada sediaan gel bertujuan untuk mengetahui keamanan sediaan saat digunakan agar tidak mengiritasi kulit. Sediaan topikal sebaiknya memiliki $\mathrm{pH}$ yang berada dalam rentang $\mathrm{pH}$ balance kulit yaitu 4,5-6,5 (Tranggono and Latifah, 2007). Berdasarkan hasil pengujian $\mathrm{pH}$, kedua sediaan gel yakni sediaan gel niosom alpha arbutin dan sediaan gel alpha arbutin tanpa sistem niosom memiliki pH yang berada pada rentang 6-6,5 yang mana kedua gel tersebut berada dalam rentang aman untuk digunakan. Nilai $\mathrm{pH}$ tidak boleh terlalu asam karena dapat menyebabkan iritasi pada kulit sedangkan jika $\mathrm{pH}$ terlalu basa dapat menyebabkan kulit bersisik (Budiman, 2008).

\section{Uji difusi gel}

Uji difusi gel dilakukan 3 kali replikasi menggunakan sel difusi franz tipe flow-trough secara in vitro dengan lepasan kulit ular yang bertujuan untuk mengetahui kadar alpha arbutin yang mampu berpenetrasi melewati stratum korneum selama interval waktu tertentu. Lepasan kulit ular dipilih karena memiliki stratum korneum dengan ketebalan, komposisi lipid yang mirip dengan kulit manusia 
serta memiliki nilai koefisien permeabilitas yang mendekati kulit manusia (Ngawhirunpat et al., 2004, Priprem et al., 2008). Koefisien permeabilitas kulit manusia adalah $1,30 \times 10^{-3} \mathrm{~cm} . \mathrm{j}^{-1}$ sedangkan koefisien permeabilitas lepasan kulit ular $1,18 \times 10^{-3} \mathrm{~cm} . \mathrm{j}^{-1}$ (Rivire et al., 2006).

Berdasarkan hasil uji difusi yang dilakukan dapat dilihat pada Gambar 2, Jumlah kumulatif persen difusi alpha arbutin dalam sediaan gel yang dibuat dalam sistem niosom selama 8 jam lebih tinggi dibandingkan sediaan gel alpha arbutin tanpa sistem niosom yakni sebesar 99,09\% $\pm 0,17$ sedangkan jumlah kumulatif persen difusi gel alpha arbutin tanpa sistem niosom selama 8 jam sebesar $73,00 \% \pm 0,94$

Hasil analisis menunjukkan bahwa terdapat perbedaan nilai persen difusi yang signifikan antara formula gel alpha arbutin dan formula gel niosom alpha arbutin. Hal tersebut menunjukkan bahwa alpha arbutin yang dibuat dalam sediaan gel dengan sistem niosom dapat meningkatkan penetrasi alpha arbutin melewati stratum korneum dibandingkan dengan sediaan gel yang mengandung alpha arbutin tanpa sistem niosom.

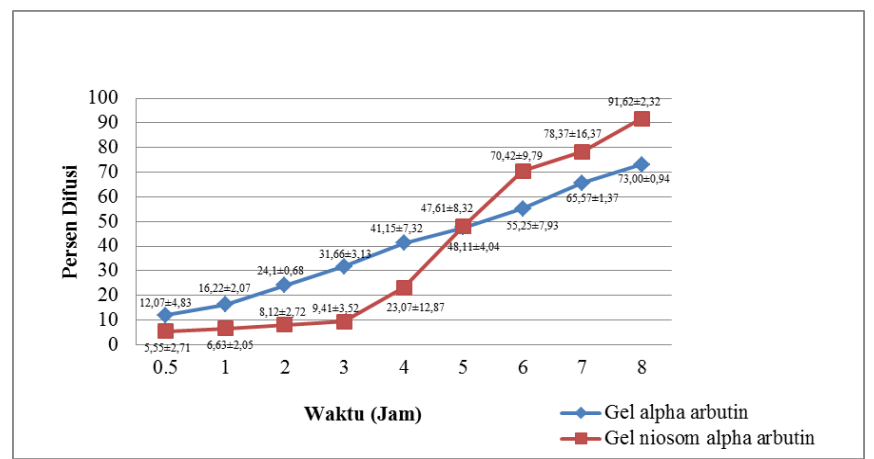

Gambar 2. Grafik hasil uji difusi sediaan gel niosom alpha arbutin dan gel alpha arbutin

\section{KESIMPULAN}

Niosom alpha arbutin dengan Konsentrasi span $60(100 \mu \mathrm{moL})$ dapat menghasilkan efisiensi penjeratan yang optimal dengan nilai efisiensi penjeratan sebesar 99,09\% $\pm 0,17$. Penggunaan span 60 dalam sediaan gel niosom alpha arbutin terbukti dapat meningkatkan penetrasi alpha arbutin secara in vitro dengan jumlah kumulatif persen difusi selama 8 jam sebesar 91,62\% $\pm 2,32$ dibandingkan gel alpha arbutin tanpa sistem niosom sebesar 73,00\% $\pm 0,94$.

\section{UCAPAN TERIMA KASIH}

Terima kasih diucapkan kepada Laboratorium Teknologi (Labtek) VII Sekolah Farmasi ITB atas fasilitas laboratorium yang diberikan.

\section{DAFTAR PUSTAKA}

Avadi, M.R., 2010, Preparation and characterization of insulin nanoparticles using chitosan and arabic gum with ionic gelation method, Nanomed Nanotech Biol Med, 6, 6-58.

Budiman, M.H., 2008, Uji sifat fisik dan aktivitas antioksidan sediaan krim yang mengandung ekstrak kering tomat (Solanum lycopersicum L.), Depok, Universitas Indonesia.

Choi, M.J., Maibach, H.I., 2005, Liposomes and niosomes as topical drug delivery systems, skin pharmacology and physiology, J Pharm Bio Res, 18(5) 209-219.

Kailas, T.d., Wendy,H.C., 2003, Development and validation of in vitro release test for semisolid dosage form-case study, Dissolution Tecnologies, 10-15.

Kshitij, B., Makeshwar, Suraj, R.W., 2013, Niosome: a novel drug delivery system, Asian J. Pharm Res, 3(1) 16-20. 
Lestiawati, V., 2015, Penggunaan span 40 sebagai penyusun niosom natrium askorbil fosfat dalam sediaan gel terhadap penetrasinya secara in vitro, Skripsi, Fakultas Kedokteran, Universitas Tanjungpura Pontianak, 45-46.

Lund, W., 1994, The Pharmaceutical codex, $12^{\text {th }}$ edition. London, The Pharmaceutical Press., 134-135

Lusi, N., 2015, Formulasi dan evaluasi gel ibuprofen dengan menggunakan viskolam sebagai gelling agent, J Kes Bakti Tunas Husada, 14(1) 47-51.

Ngawhirunpat, T., Panomsuk, S., Opanasopit, P., Rojanarata, T., Hatanaka, T., 2004, Comparison of the percutaneous absorption of hydrophilic and lipophilic compounds in shed snake skin and human skin, Pharmazie, 61(4) 5-331.

Priprem, A., Khamlet, C., Pongjanyakul, T., Radapong, S., Rittirod, T., Chitopras, P., 2008, Comparative permeation studies between scale region of shed snake skin and human skin in vitro, Am J Agril Biol Sci, 3(2) 444-450.

Rahman, Latifah, Ismail, I., Wahyudin, E., 2011, Kapasitas jerap niosom tehadap ketoprofen dan prediksi penggunaan transdemal, Majalah Farmasi Indonesia, 22 (2) 85-91.

Rivire, J.E., Menteiro-Reviere, N.A., 2006, Dermal absorbtion models in toxycology and pharmacology. Amerika, Taylor \& Francis Group., 317.

Rowe, R.C., Sheskey, P.J., Owen, S.C., 2009, Handbook of pharmaceutical excipients, Fifth edition. London, Pharmaceutical Press., 178-754.

Sahin, N.O., 2007, Niosome as nanocarrier systems. in Mozari, M.R., Nanomaterials and nanosystems for biomedical applications, Springer, New York, 67-81.

Septiani, S,N,W., Mita S,R., 2011. Formulasi Sediaan masker gel antioksidan dari ekstrak etanol biji melinjo ( Gnetum gnemon Linn), Jurnal UNPAD, 1(1) 4-24.

Soeratri, W., Tutik, P., 2004, Penambahan asam glikolat terhadap efektivitas sediaan tabir surya kombinasi anti UV-A dan anti UV-B dalam basis gel, Majalah Farmasi Airlangga, 4 (3) 73-75.

Tranggono, R.I., dan Latifah, F., 2007, Buku pegangan ilmu pengetahuan kosmetik. Jakarta, pustaka utama. 
